\title{
Role of Ultrasound in Assessment of Menisco-Ligamentous Injuries of Knee Joint in Comparison with Magnetic Resonance Imaging
}

\author{
SALLY M.A. HUSSEIN, M.Sc.; MARWA I. FAHMY, M.D. and KHALED A. MOHAMED ALI, M.D. \\ The Department of Radiology, Faculty of Medicine, A in Shams University
}

\begin{abstract}
Background: While considering the Magnetic Resonance Imaging (MRI) as 'gold standard' for detection of knee ligamentous and meniscal injuries, we are determining the usefulness of Ultrasound (US) in various knee injuries and correlate the findings of US with the findings of MRI.
\end{abstract}

Aim of Study: to assess the diagnostic utility of ultrasound in patient with suspected ligaments or menisci injuries of knee joint keeping MRI as the Gold standard.

Material and Methods: This prospective study included 30 patients who were referred to the Radiology Department with clinically suspected meniscal/ligamentous injury of the knee. After detailed clinical examination, US examination of the involved knee was performed together with an examination of the contralateral normal knee, followed by MRI of the symptomatic knee in all 30 patients. The MRI findings were considered as final. Sensitivity and specificity for ultrasound in knee injuries was calculated with correlation with MRI.

Results: In the present study, the majority of patients were in age group $18-57$ years, $70 \%$ were males and $30 \%$ were females (of a total of 30 patients). A total of 30 patients were diagnosed as having ligamentous/meniscal tears on US and MRI. In the diagnosis of meniscal/ligamentous tears, the strength of agreement between US and MRI was good.

Conclusion: US of the knee shows promising results in the diagnosis of meniscal/ligamentous tears. A wide availability, cost effectiveness and better tolerability of US make it a modality of first choice for evaluating knee injuries.

Key Words: Meniscus - Ligament - Knee injury.

\section{Introduction}

THE knee joint is a type of compound synovial joints. The ligaments constitute the major supporting framework of the knee joint. Due to limited bony support, stability of the joint is highly dependent upon the ligaments, cartilages, tendons

Correspondence to: Dr. Sally M.A. Hussein, The Department of Radiology, Faculty of Medicine, Ain Shams University and menisci and the same are more prone to injuries [1].

Knee injuries are common, especially when taking part in sports. Injuries to soft tissues, such as ligaments, cartilage and tendons are commonly encountered. Damage to the bone also can occur. One of the most common mechanisms for knee injury is direct trauma, which is commonly seen in athletic injuries [2].

Proper knee function relies on multiple ligaments that provide stability during force transmission across the joint. Although there are various secondary stabilizers, ligaments are the primary restraints against anterior, posterior, varus, and valgus forces. The Anterior Cruciate Ligament (ACL); Posterior Cruciate Ligament (PCL); medial, or tibial, collateral ligament (MCL); lateral, or fibular, collateral ligament (LCL); Medial Patellofemoral Ligament (MPFL); and (controversial) Anterolateral Ligament (ALL) are the most frequently discussed knee ligaments [3].

Clinical examination even by the most experienced staff using the strictest of clinical methods is not always enough to diagnose knee injuries. Arthroscopy has been considered as the gold standard for the diagnosis of knee injuries, but is invasive, expensive and requires day surgery admission [4].

Magnetic Resonance Imaging (MRI) is now the non invasive gold standard for the diagnosis of knee injuries but MRI has long examination times, and is expensive. Yet due to its superior soft tissue contrast, multiplanar capabilities and lack of ionizing radiation, MRI is a well-suited tool for evaluation of knee ligaments. Strict attention to 
imaging technique is imperative, however, in order to provide accurate and reproducible assessment of ligament integrity, as well as to detect associated complications, including meniscal and chondral injuries. While the capabilities of MRI in assessing the static and dynamic stabilizers of the knee joint are well founded, it is important for the referring clinician to correlate MRI findings with the clinical assessment of functional ligament stability [5]

Ultrasound (US) is a becoming a leading imaging modality in the evaluation of the musculoskeletal system as it is readily available and economical. US evaluates the fibrillar anatomy of muscles, cartilages, tendons and ligaments. Other advantageous of US are ability to compress, dynamically assess structures and compare easily with the contralateral side. There have been studies done in the past that evaluated the accuracy of either US or MRI in detection of knee injuries and only few studies compared these two methods [6].

As a result, recent studies have demonstrated point-of-care ultrasound as an alternative, noninvasive and real-time imaging modality to evaluate the soft tissue pathology of the knee, including injuries to the medial meniscus and Medial Collateral Ligament (MCL) [7].

There are also limitations to using ultrasound. There is a relatively steep learning curve and dependence on the training, skill, and experience of the operator [8].

We done double blinded, prospective study to assess the effectiveness of US in diagnosis of knee injuries and compare the results with MRI.

\section{Patients and Methods}

This prospective study was conducted on patients referred from the orthopedic clinic to Ultrasound Unit at Ain Shams University Hospitals for US examination of knee joint followed by MRI of the symptomatic knee in all patients.

About 30 patients were included ( 9 females \& 21 males) and their age ranged from 18 to 57 years. This study was carried out from January 2019 to July 2019.

The patients who were clinically suspected of knee ligamentous or meniscal injuries were included in the study. While, patients with contraindications to MRI, those with known or diagnosed fracture/dislocation involving the knee on plain radiography and who had undergone knee surgery for any reason were excluded from the study.

\section{MRI technique:}

The study was performed on super conductive MRI scanner (Philips Achieva-XR 1.5 Tesla) using standard scanning protocol:

- All metallic objects should be removed from the patient's body.

- Patient position: The patient is positioned supine on MRI table.

- Patient will be instructed about the importance of being calm with no motion throughout time of examination.

\section{- Knee protocol:}

- Patient in supine position.

- Use dedicated knee coil.

- Axials parallel to knee joint line include whole patella and fibular head.

- Coronals parallel to posterior aspect of femoral condyles include entire patella to $2 \mathrm{~cm}$ posterior to femoral condyles.

- Sagittal obliques parallel to medial aspect of lateral condyle include both collateral ligaments.

\section{Ultrasound technique:}

US evaluation of the knee is primarily performed with the patient in the supine position, with the obvious notable exception of evaluation of the posterior structures, for which the patient lies prone. Then we perform sonographic examination for the patient during standing that allow weight bearing for better detection of meniscal extrusion.

Scanning is performed with a high-frequency (ideally, $12 \mathrm{MHz}$ ) linear transducer, although a lower frequency $(7-9 \mathrm{MHz})$ transducer is sometimes better suited for evaluating the deep posterior structures.

\section{Results}

I- Demographic data and characteristics of study population: A total of 30 patients presented with knee pain were included in the study, 21 males (70\%) and 9 females (30\%). The study was conducted at Ain Shams University Hospitals over a period of 6 months from January 2019 to July 2019 . The mean age of the study group was $33.07 \pm 12.19$ years (range: $18-57$ years). All the patients included in the study underwent both MRI and Ultrasound examination for the affected knee.

II- Comparison between U/S and MRI regarding the detection of injury of the anterior horn of the lateral meniscus: Regarding the frequency, both 
Ultrasound and MRI diagnosed 3 cases (10\%) as AHLM injury.

Regarding the diagnostic performance of U/S, there was highly statistically significant association found between results of MR and US with $p$-value $<0.001$.

The 27 patients who found negative by MR was found negative by US and also the 3 positive patients by MR was found positive by US which mean sensitivity of $100 \%$, specificity of $100 \%$ ( $p$ $<0.001)$. As seen in the following table.

Table (1): Comparison between results of MR and US of AHLM.

\begin{tabular}{|c|c|c|c|c|c|}
\hline \multirow{2}{*}{$\begin{array}{l}\text { Anterior horn } \\
\text { of lateral } \\
\text { meniscus }\end{array}$} & \multicolumn{2}{|c|}{ MR } & \multicolumn{3}{|c|}{ Chi-square test } \\
\hline & Negative & Positive & $x^{2}$ & $p$-value & Sig. \\
\hline \multicolumn{6}{|l|}{$U S:$} \\
\hline Negative & $27(100.0 \%)$ & $0(0.0 \%)$ & 30.000 & 0.000 & HS \\
\hline Positive & $0(0.0 \%)$ & $3(100.0 \%)$ & & & \\
\hline
\end{tabular}

III- Comparison between U/S and MRI regarding the detection of injury of the posterior horn of the lateral meniscus: Regarding the frequency, both Ultrasound and MRI diagnosed 5 cases $(16.7 \%)$ as PHLM injury.

Regarding the diagnostic performance of U/S, there was highly statistically significant association found between results of MR and US with $p$-value $<0.001$.

The 25 patients who found negative by MR was found negative by US and also the 5 positive patients by MR was found positive by US which mean sensitivity of $100 \%$, specificity of $100 \%$ $(p<0.001)$. As seen in the following table.

Table (2): Comparison between results of MR and US of PHLM.

\begin{tabular}{|c|c|c|c|c|c|}
\hline \multirow{2}{*}{$\begin{array}{l}\text { Posterior horn } \\
\text { of lateral } \\
\text { meniscus }\end{array}$} & \multicolumn{2}{|c|}{ MR } & \multicolumn{3}{|c|}{ Chi-square test } \\
\hline & Negative & Positive & $x^{2}$ & $p$-value & Sig. \\
\hline \multicolumn{6}{|l|}{ US: } \\
\hline Negative & $25(100.0 \%)$ & $0(0.0 \%)$ & 30.000 & 0.000 & $\mathrm{HS}$ \\
\hline Positive & $0(0.0 \%)$ & $5(100.0 \%)$ & & & \\
\hline
\end{tabular}

IV- Comparison between U/S and MRI regarding the detection of injury of the anterior horn of the medial meniscus: Regarding the frequency, both Ultrasound and MRI diagnosed 6 cases $(20 \%)$ as AHMM injury.

Regarding the diagnostic performance of U/S, there was highly statistically significant association found between results of MR and US with $p$-value $<0.001$.
The 24 patients who found negative by MR was found negative by US and also the 6 positive patients by MR was found positive by US which mean sensitivity of $100 \%$, specificity of $100 \%$ $(p<0.001)$. As seen in the following table.

Table (3): Comparison between results of MR and US of AHMM.

\begin{tabular}{lllllll}
\hline $\begin{array}{l}\text { Anterior horn } \\
\text { of medial } \\
\text { meniscus }\end{array}$ & \multicolumn{3}{c}{ MR } & & \multicolumn{3}{c}{ Chi-square test } \\
\cline { 2 - 3 } & Negative & Positive & & $x^{2}$ & $p$-value & Sig. \\
\hline $\begin{array}{l}\text { Negative } \\
\text { Positive }\end{array}$ & $\begin{array}{l}24(100.0 \%) \\
0(0.0 \%)\end{array}$ & $0(0.0 \%)$ & 30.000 & 0.000 & HS \\
\hline
\end{tabular}

$\mathrm{V}$ - Comparison between U/S and MRI regarding the detection of injury of the posterior horn of the medial meniscus: Regarding the frequency, U/S diagnosed 15 cases (50\%) and MRI diagnosed 18 cases $(60 \%)$ as PHMM injury.

Regarding the diagnostic performance of U/S, there was highly statistically significant association found between results of MR and US with $p$-value $<0.001$.

The 12 patients who found negative by MR was found 15 patients by US and the 18 positive patients by MR was found 15 by US which mean sensitivity of $83.3 \%$, specificity of $100 \%(p<0.001)$. As seen in the following table.

Table (4): Comparison between results of MR and US of PHMM.

\begin{tabular}{|c|c|c|c|c|c|}
\hline \multirow{2}{*}{$\begin{array}{l}\text { Posterior horn } \\
\text { of medial } \\
\text { meniscus }\end{array}$} & \multicolumn{2}{|c|}{ MR } & \multicolumn{3}{|c|}{ Chi-square test } \\
\hline & Negative & Positive & $x^{2}$ & $p$-value & Sig. \\
\hline \multicolumn{6}{|l|}{$U S:$} \\
\hline Negative & $12(100.0 \%)$ & $3(16.7 \%)$ & 20.000 & 0.000 & HS \\
\hline Positive & $0(0.0 \%)$ & $15(83.3 \%)$ & & & \\
\hline
\end{tabular}

VI- Comparison between U/S and MRI regarding the detection of meniscal injury: Demonstrating the frequency of injury of anterior and posterior horn of the menisci according to MRI and ultrasound features.

Table (5): Comparison between results of MRI and US in detection of meniscal injury.

\begin{tabular}{|c|c|c|c|c|c|}
\hline & Ultrasound & & MRI & $p$-value & Significance \\
\hline AHMM & $6 \quad(20.0 \%)$ & 6 & $(20.0 \%)$ & 1 & NS \\
\hline PHMM & $15(50.0 \%)$ & 18 & $(60.0 \%)$ & 0.436 & NS \\
\hline AHLM & $3 \quad(10.0 \%)$ & 3 & $(10.0 \%)$ & 1 & NS \\
\hline PHLM & $5 \quad(16.7 \%)$ & 5 & $(16.7 \%)$ & 1 & NS \\
\hline Total no. & $29(24.2 \%)$ & & $(26.7 \%)$ & 0.656 & NS \\
\hline
\end{tabular}

NS: Non Significant. 
The previous table shows that there was no statistically significant difference between U/S \& MRI in detection of meniscal injury.

VII- Comparison between U/S and MRI regarding the detection of collateral ligaments: Regarding the frequency, U/S diagnosed 12 cases (40\%) and MRI diagnosed 15 cases (50\%) as collateral ligaments injury.

Regarding the diagnostic performance of U/S, there was highly statistically significant association found between results of MR and US with $p$-value $<0.001$.

The 15 patients who found negative by MR was found negative by US while the 15 positive patients by MR was found 12 positive patients by US which mean sensitivity of $80 \%$, specificity of $100 \%(p<0.001)$. As seen in the following table.

Table (6): Comparison between results of MR and US of collateral ligaments.

\begin{tabular}{lllllll}
\hline \multirow{2}{*}{$\begin{array}{l}\text { Collateral } \\
\text { ligaments }\end{array}$} & \multicolumn{2}{c}{ MR } & & \multicolumn{3}{c}{ Chi-square test } \\
\cline { 2 - 3 } \cline { 5 - 6 } & Negative & Positive & & $x^{2}$ & $p$-value & Sig. \\
\hline$U S:$ & & & & & \\
Negative & $15(100.0 \%)$ & $3(20.0 \%)$ & 20.000 & 0.000 & HS \\
Positive & $0(0.0 \%)$ & $12(80.0 \%)$ & & & \\
\hline
\end{tabular}

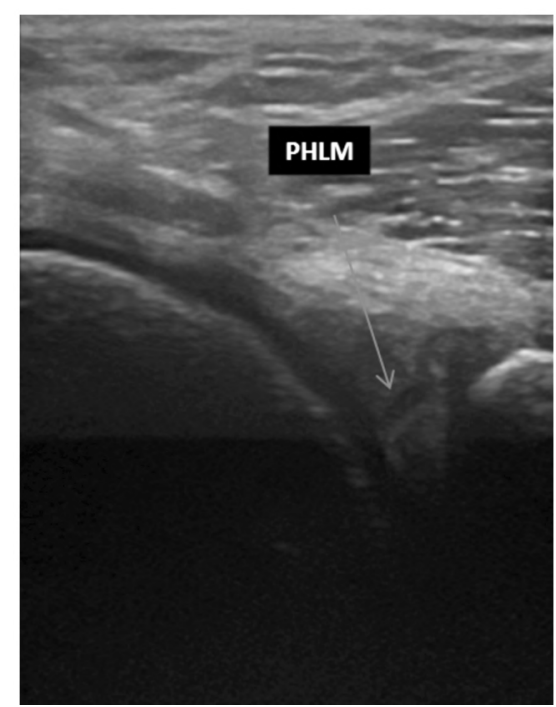

(A)
VIII- Comparison between U/S and MRI regarding the detection of Cruciate ligaments: Regarding the frequency, U/S diagnosed 3 cases $(10 \%)$ and MRI diagnosed 21 cases (70\%) as PHMM injury.

Regarding the diagnostic performance of U/S, there was no statistically significant association found between results of MR and US with $p$-value $>0.05$.

The 9 patients who found negative by MR was found negative by US and the 21 positive patients by MR was found 3 positive patients by US which mean sensitivity of $14.3 \%$, specificity of $100 \%$ with $p$-value $>0.05$. As seen in the following table:

Table (7): Comparison between results of MR and US of cruciate ligaments.

\begin{tabular}{|c|c|c|c|c|c|}
\hline \multirow{2}{*}{$\begin{array}{l}\text { Cruciate } \\
\text { ligaments }\end{array}$} & \multicolumn{2}{|c|}{ MR } & \multicolumn{3}{|c|}{$\begin{array}{c}\text { Chi-square } \\
\text { test }\end{array}$} \\
\hline & Negative & Positive & $x^{2}$ & $p$-value & Sig. \\
\hline \multicolumn{6}{|l|}{$U S:$} \\
\hline Negative & $9(100.0 \%)$ & $18(85.7 \%)$ & 1.429 & 0.000 & HS \\
\hline Positive & $0(0.0 \%)$ & $3(14.3 \%)$ & & & \\
\hline
\end{tabular}

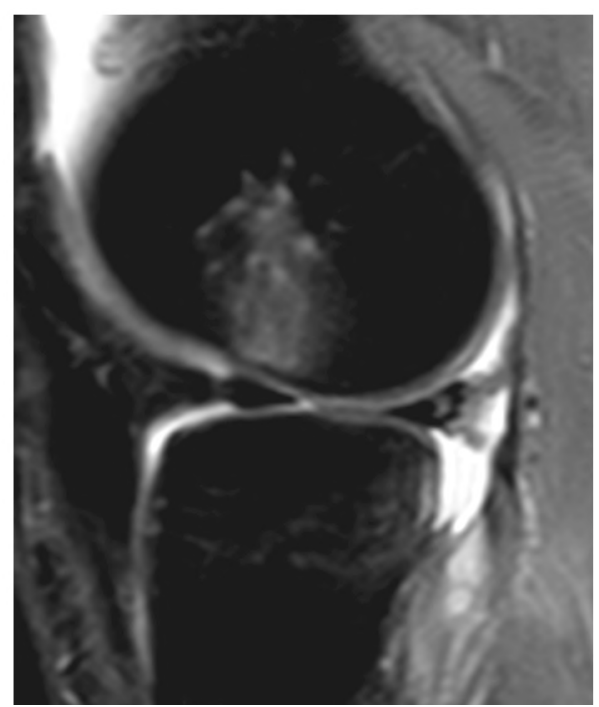

(B)

Fig. (1): 20 years old male patient presented with right knee swelling \& pain on movement with history of trauma 2 weeks ago, Ultrasonography of right knee was done (A), PHLM shows Vertical hypo echoic fissure seen interrupting the outer zone of the PHLM reaching the inferior articular margins suggestive of vertical tear. MRI of right knee was done (B), PDW-TSE -SPAIR sagital image, PHLM shows a vertical band of high SI on STIR disrupting its fibers from the superior to the inferior articular surfaces denoting vertical tear. 


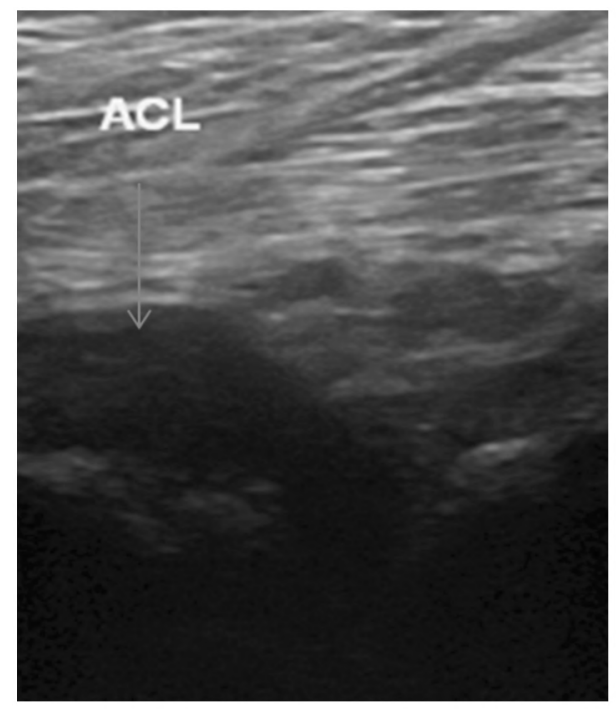

(A)

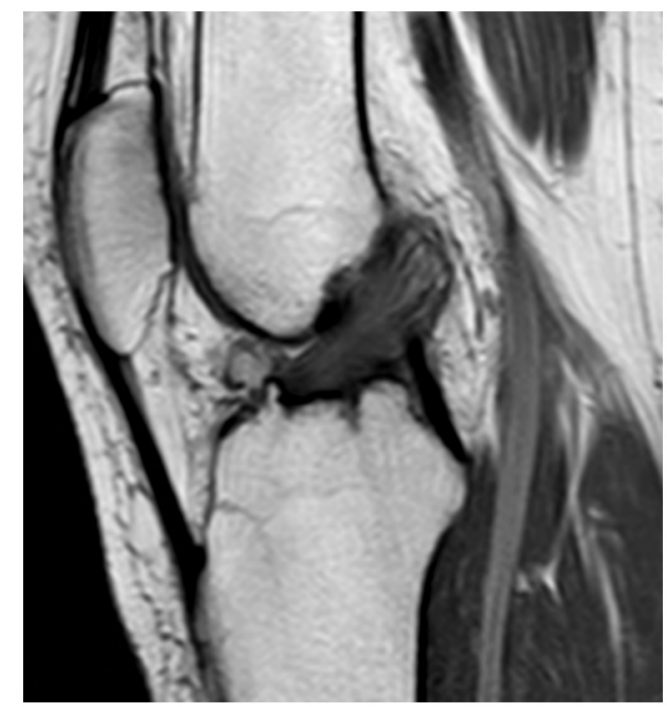

(B)

Fig. (2): 39 years old female patient presented by right knee pain and inability to flex the knee 5 month ago with progressive coarse. Ultrasonography of right knee was done (A), ACL is thickened at its femoral attachment suggesting degeneration. MRI of right knee was done, PDW-TSE sagital image, ACL shows mucoid degeneration with surrounding intra and peri ligamentous ganglion cysts.

\section{Discussion}

This study included 30 patients referred to MRI Unit of Radio-diagnosis Department at Ain Shams University Hospitals.

The age of patients ranged from 18 to 57 years old with mean age $33.07 \pm 12.19$ years.

The study revealed that specificity of U/S in the diagnosis of anterior horn of lateral meniscus tear was about $100 \%$, and this goes with Singh et al., [12] in which specificity of U/S in the diagnosis of anterior horn of lateral meniscus tear was about $100 \%$. While sensitivity of U/S in the diagnosis of anterior horn of lateral meniscus tear was about $100 \%$, and this is higher than that of Singh et al., [12] in which sensitivity of U/S in the diagnosis of anterior horn of lateral meniscus tear was only about $66.67 \%$.

Our study also revealed that sensitivity of U/S in the diagnosis of posterior horn of lateral meniscus tear is about $100 \%$, and this is also higher than that shown by the study of Singh et al., [12] in which sensitivity of U/S in the diagnosis of posterior horn of lateral meniscus tear was about $62.57 \%$. While specificity of U/S in the diagnosis of posterior horn of lateral meniscus is about $100 \%$ which goes with Singh et al., [12] in which specificity of $\mathrm{U} / \mathrm{S}$ in the diagnosis of posterior horn of lateral meniscus tear was $97.62 \%$.

The study revealed that sensitivity and specificity of U/S in the diagnosis of anterior horn of medial meniscus tear were about $100 \%$, and this agreed with Singh et al., [12] in which sensitivity and specificity of U/S in the diagnosis of anterior horn of medial meniscus were about $100 \%$.

The study revealed that sensitivity and specificity of U/S in the diagnosis of posterior horn of medial meniscus tear were about $83.3 \%$ and $100 \%$ respectively and this is in concordance with the study done by El-Monem et al., [13] in which sensitivity and specificity of U/S in the diagnosis of posterior horn of medial meniscus tear were about $81 \%$ and $77 \%$ respectively.

The study revealed that sensitivity and specificity of U/S in the diagnosis of collateral ligaments injury were about $80 \%$ and $100 \%$ respectively and this is in concordance with the study done by Singh et al., [12] in which sensitivity and specificity of $\mathrm{U} / \mathrm{S}$ in the diagnosis of posterior horn of medial meniscus tear were about $83.33 \%$ and $97.73 \%$ respectively.

The study revealed that sensitivity and specificity of U/S in the diagnosis of cruciate ligaments injury were about $14.3 \%$ and $100 \%$ respectively and this is in against the study done by El-Monem et al., [13] in which sensitivity and specificity of $\mathrm{U} / \mathrm{S}$ in the diagnosis of posterior horn of medial meniscus tear were about $82.35 \%$ and $93.94 \%$ respectively.

To summarize, our study results agreed with other studies in some points and were different in other points, this may be attributed to difference 
in the sample size or difference in age group patients included in the studies.

During the study we found that it's more difficult to detect meniscal tear among old age group due to associated meniscal degeneration.

Despite advantages, there are some limitations of this technology. US is considered to be an operator-dependent technology. Acquisition of US skills takes time depending on trainee's hand-eye coordination skills. A long training period may be an important limiting factor in its popular use.

Another limitation of the study was the small number of included patients. So, further studies with larger number of patients for better and more reliable results are recommended.

\section{Conclusion:}

US is highly sensitive and specific in detection of meniscal tear as well as the detection on collateral ligaments injury in correlation to MRI. While it is less sensitive but still specific in detection of cruciate ligament injury in correlation to MRI so, they can be used as non invasive method for screening of patients with knee pain for meniscoligamentous injuries.

\section{References}

1- AMANDEEP S., INDERMEET M. and THUKRAL K. Diagnostic Accuracy of Ultrasonography in Evaluation of Knee Injuries with Magnetic Resonance Imaging Correlation, International Journal of Anatomy, Radiology and Surgery, Vol. 7 (1), 2018.

2- PETSCAVAGE-THOMAS J. and WISSMAN R.D.: Clinical applications of dynamic functional musculoskeletal ultrasound. Dove Press Journal. Reports in Medical Imaging, 7: 27-39, 2014.

3- BEDI A., LaPRADE R. and BURRUS M.: Radiographic And Anatomic Landmarks of The Major Knee Ligaments, The Journal of Bone and Joint Surgery, 100: 1241-50, 2018.

4- JAMES L. COOK, CRISTI R. COOK and JAMES P. STANNARD: MRI versus Ultrasonography to Assess Meniscal Abnormalities in Acute Knees, The Journal of Knee Surgery, Vol. 27 (4), 2014.

5- Potter, Sneag, Chong. Chapter 7 MRI Evaluation of Knee Ligaments, Potter 2012.

6- GHOSH N. and KRUSE D.: Comparing Point-of-careultrasound (POCUS) to MRI for the Diagnosis of Medial Compartment Knee Injuries, Journal of Medical Ultrasound, 25: 167e 172, 2017.

7- RAZEK A., FOUDA N. and ELMETWALEY N.: Sonography of the knee joint. J. Ultrasound, 12 (2): 53e60, 2009.

8- LEE D. and BOUFFARD J.: Ultrasound of the knee. Eur. J. Ultrasound, 14 (1): $57 \mathrm{e} 71$.

9- NADAFI J.B.S. and ALT value of sonography with micro convex probes in diagnosingmeniscal tears compared with arthroscopy. J.U.M., 25 (5): 593e7.7, 2006.

10- RODKEY W.G.: Basic biology of the meniscus and response to injury. Instr. Course Lect., 49: 189-93, 2010.

11-SUDOL-SZOPINSKA I., JANS L. and TEH J.: Rheumatoid arthritis: What do MRI and ultrasound show. J Ultrasound., 17: 5-16, 2017.

12- SINGH A., MANGAT I., THUKRAL C.L. and GUPTA K.: Diagnostic Accuracy of Ultrasonography in Evaluation of Knee Injuries with Magnetic Resonance Imaging Correlation, 7, 2016.

13-ABDEL EL-MONEM S. and MOANES M.: Comparative study between high resolution ultrasound (hrus) and MRI in diagnosis of meniscal and cruciate ligaments injury of the knee. Med. J. Cairo Univ., 80 (2): 233-42, 2012. 


\section{دور الموجات فوق الصوتية في تقييم الآربطة والغضاريف

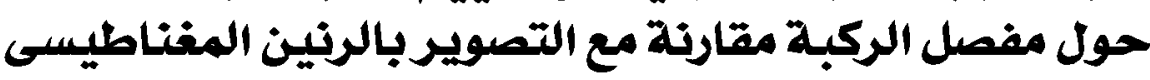

مفصل الركبة هو نوع من المفاصل الزلالية المركبة. تشكل الآربطة الإطار الداعم الرئيسى لمفصل الركبة. بسبب الدمم العظمى المحدود، يعتمد إستقرار المفصل بشكل كبير على الآربطة والفضاريف والآوتار.

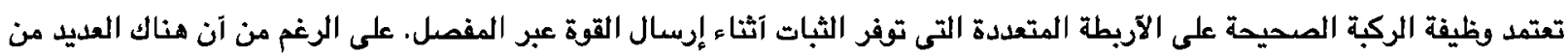

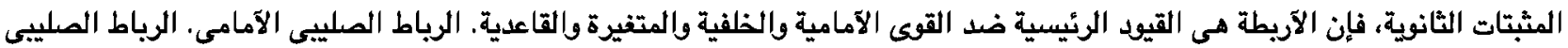

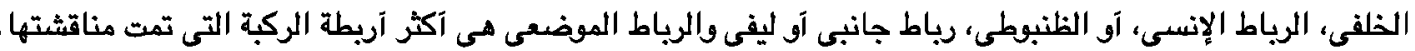

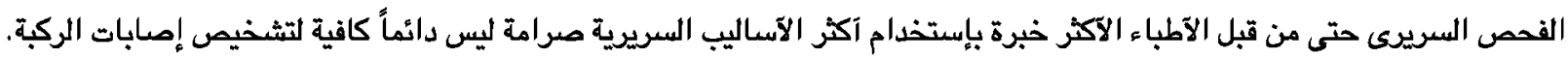

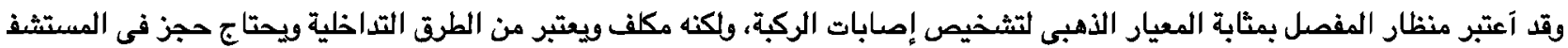

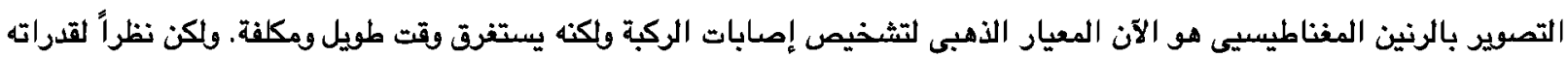

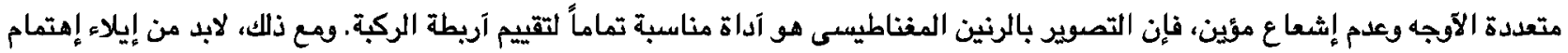

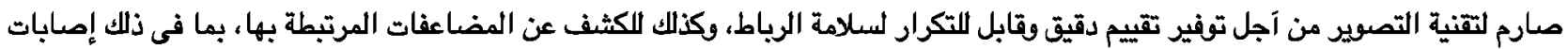

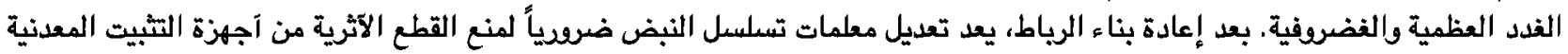

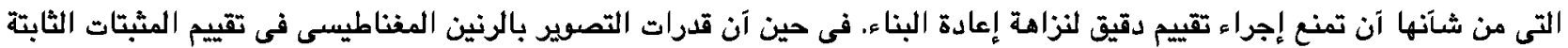

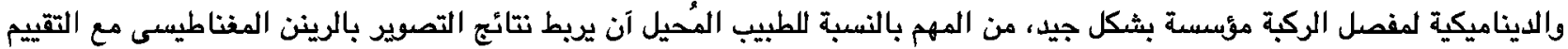
السريرى لإستقرار الرباط الوظيفى.

يعد التصوير بالموجات فوق الصوتية عائى الدقة بمثابة طريقة تصوير رائدة فى تقييم الجهاز العضلى الهيكلى حيث آنه متوفر وإقتصادى.

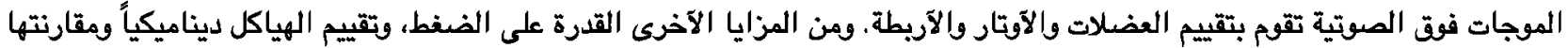
بسهولة مع الجانب المقابل.

والغرض من هذه الدراسة هو تصديد الفائدة الإكلينيكية من الموجات فوق الصوتية لتشخيص آمراض الفضروف الهئ الهلالى والآربطة فى

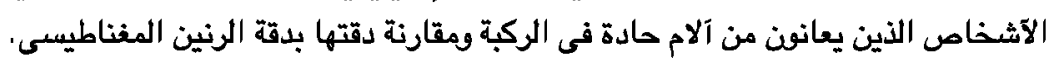

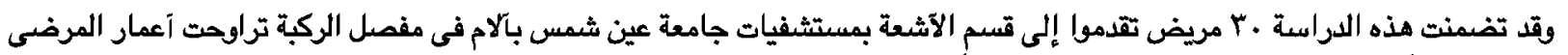

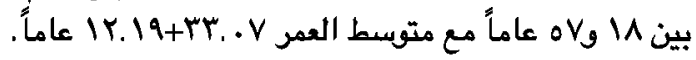

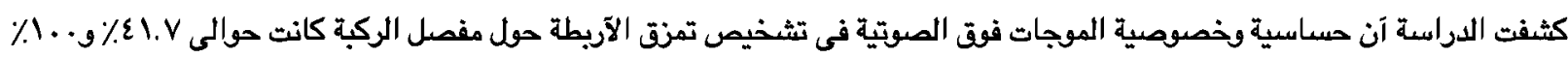
على التوالى.

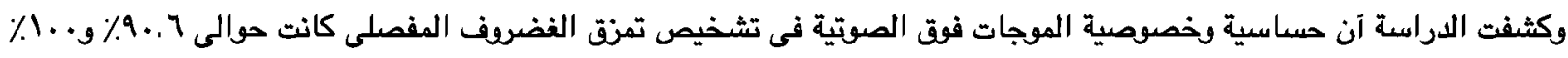
على التوالى، وبالتالى توصلنا إلى آنه يمكن إستخدام الموجات الفوق صوتية فى التشخيص المبدئى لإصابة الغضروف الهلالئ. 